\title{
Pressure Sensor with New Electrical Circuit Utilizing Bipolar Junction Transistor
}

\section{Mikhail Basov ( $\nabla$ engineerbasovm@gmail.com )}

Dukhov Automatics Research Institute (VNIIA) https://orcid.org/0000-0003-0798-4500

\section{Research Article}

Keywords: MEMS, pressure sensor, differential amplifier, bipolar junction transistor, high sensitivity, temperature compensation

Posted Date: December 15th, 2021

DOI: https://doi.org/10.21203/rs.3.rs-1169225/v1

License: (c) (1) This work is licensed under a Creative Commons Attribution 4.0 International License. Read Full License 


\section{Abstract}

High sensitivity MEMS pressure sensor chip for different ranges (1 to $60 \mathrm{kPa}$ ) utilizing the novel electrical circuit of piezosensitive differential amplifier with negative feedback loop (PDA-NFL) is developed. Pressure sensor chip PDA-NFL utilizes two bipolar-junction transistors (BJT) with vertical $n-p-n$ type structure (V-NPN) and eight piezoresistors ( $p$-type). Both theoretical model of sensor response to pressure and temperature and experimental data are presented. Data confirms the applicability of theoretical model. Introduction of the amplifier allows for decreasing chip size while keeping the same sensitivity as a chip with classic Wheatstone bridge circuit.

\section{Introduction}

Piezoresistive pressure sensors are dominating in the pressure sensing market (automotive, medical, process control nuclear energy, aviation \& space) and attracting a lot of R\&D resources. The development of MEMS pressure sensors follows well-known trends in microelectronics, including chip size reduction while maintaining or improving sensor performance. The chip size reduction allows for chip and sensor cost reduction. Most of piezoresistive sensors use Wheatstone bridge electrical circuit with p-type resistors (PRs). Increase of sensor sensitivity while keeping the same chip size is one of the top priorities in sensor development. Researchers tried to solve this task by changing chip mechanical structure and PRs arrangement [1-19]. There are many attempts to combine wet etching (by $\mathrm{KOH}$ or TMAH) or/and deep reactive ion etching (DRIE) to create novel diaphragm structures. There are examples of significant size reduction of pressure sensor chips manufactured in medium and high volumes [20,21]. Sensing elements with profiled diaphragms can have high pressure sensitivity and linearity combined with small temperature errors. For example, sensing elements with very high pressure sensitivity demonstrated by Xi'an Jiaotong University [22,23]. However, sensitivity increase and chip size decrease by reducing membrane size and thickness has both process and design limitations. Further size reduction of pressure sensing elements can be achieved by adding active elements - transistors - and increasing the number of PRs in the electrical circuit. This work presents a pressure sensor chip (Fig. 1) with novel electrical circuit utilizing piezosensitive differential amplifier on bipolar junction transistors (BJT) with negative feedback loop (PDA-NFL) [24-29]. Circuit design and microstructure design allows for both significant increase of the sensitivity and for compensation of temperature errors. Performance of the PDA-NFL pressure sensing element is compared to other pressure sensing elements for three differential pressure ranges $(1 \mathrm{kPa}, 5 \mathrm{kPa}$ and $60 \mathrm{kPa})$.

\section{li. Theoretical And Technological Aspects}

PDA-NFL pressure sensor chip was designed using both results obtained from an analytical mathematical model and from software modeling. Both lateral $p-n-p$ type (L-PNP) and vertical n-p-n type (V-NPN) BJTs located on the membrane and on the frame (sensitive / not sensitive to pressure) were analyzed and included in the designs. Electrical circuit with NPN transistors used in the sensor chip is shown in Fig. 1a. Values of PRs and operating point of BJTs providing good balance between sensitivity 
and temperature compensation were determined analytically. Sentaurus TCAD software was used to finalize technological details. A process flow where all PRs, base of V-NPN BJT, emitter and collector of LPNP BJT are created in one process step by diffusion of boron $\left(\mathrm{p}^{-}\right)$was chosen. The $\mathrm{p}^{-}$layer has surface concentration $\mathrm{N}_{\mathrm{S}}=6 \cdot 10^{18} \mathrm{~cm}^{-3}$ (sheet resistance $200 \mathrm{Ohm} / \mathrm{sq} ., \mathrm{p}-\mathrm{n}$ junction depth $2.2 \mu \mathrm{m}$ ). This allows for making PRs with high sensitivity to stress (piezoresistive coefficient $\pi_{44}=1,26 \cdot 10^{-9} \mathrm{~Pa}^{-1}$ for [110] direction). Phosphorous doping $\left(\mathrm{n}^{+}\right)$and drive-in were selected based on the target parameters of transistors. V-NPN BJT was designed to have gain $\beta_{V-N P N}=150$, base current $\mathrm{l}_{\mathrm{b} \text { V-NPN }}=5 \mu \mathrm{A}$ and collectorbase voltage drop of $0.80 \mathrm{~V}$. L-PNP BJT had target gain $\beta_{\mathrm{L}-\mathrm{PNP}}=5$, base current $\mathrm{I}_{\mathrm{b}} \mathrm{L}-\mathrm{PNP}=50 \mu \mathrm{A}$; and collector-base voltage drop of $0.86 \mathrm{~V}$ (Fig. 2). All parameters of electrical circuit PDA-NFL presented in Table I. Four pairs of PRs placed in the areas with high mechanical stress (MS) selected with help of modeling in ANSYS (Fig. 3b). The target values of PRs were obtained by changing their length, while width of all eight PS was chosen to be $10 \mu \mathrm{m}$. $\mathrm{P}^{-}$regions of PRs formed on the thin part of the membrane connected to metal lines on the frame by $\mathrm{P}^{+}$areas. The chip uses Al-Si $(1.5 \% \mathrm{Si})$ metallization. The PR resistances change as shown on Fig. 1a in response to applied pressure.

Pressure sensor chips were manufactured using (100) p-type Si wafers with n-type epitaxial layer. Required isolation of the BJTs was achieved by deep diffusion of $\mathrm{p}^{+}$regions. The dimensions of pressure sensor chip with PDA-NFL are $4.0 \times 4.0 \times 0.4 \mathrm{~mm}^{3}$. It has square membrane with three rigid islands (RIs) formed by anisotropic wet etching in $\mathrm{KOH}$ (Fig. 3a and Table II). Sensors for three different pressure ranges: $60 \mathrm{kPa}, 5 \mathrm{kPa}$ and $1 \mathrm{kPa}$ have been manufactured.

Table I. Parameters of PDA-NFL circuit. 


\begin{tabular}{|c|c|c|c|c|}
\hline \multirow[t]{2}{*}{ Parameters } & \multicolumn{2}{|c|}{ V-NPN circuit } & \multicolumn{2}{|c|}{ L-PNP circuit } \\
\hline & Analytical & Multisim & Analytical & Multisim \\
\hline Base current BJT I $I_{b}, \mu A$ & 5.0 & 4.6 & 50.0 & 44.0 \\
\hline Gain BJT $\beta$ & 150 & 145 & 5 & 5 \\
\hline Base-emitter voltage drop BJT $\left(U_{b}-U_{e m}\right), V$ & 0.80 & 0.80 & 0.78 & 0.77 \\
\hline Collector-base voltage drop BJT $\left(U_{c}-U_{b}\right), V$ & 0.81 & 0.80 & 0.86 & 0.86 \\
\hline Collector potential BJT $\mathrm{U}_{\mathrm{C}} \mathrm{V}$ & 2.50 & 2.79 & 2.50 & 2.81 \\
\hline Parasitic current to substrate BJT I $I_{p a r} \mu \mathrm{A}$ & - & & 33.0 & \\
\hline $\mathrm{R}_{\mathrm{b} 11, \mathrm{~B} 21}, \mathrm{kOhm}$ & 4.47 & & 3.00 & \\
\hline $\mathrm{R}_{\mathrm{b} 12, \mathrm{~B} 22}, \mathrm{kOhm}$ & 2.98 & & 2.00 & \\
\hline $\mathrm{R}_{\mathrm{c} 1, \mathrm{c} 2}, \mathrm{kOhm}$ & 3.33 & & 10.00 & \\
\hline $\mathrm{R}_{\mathrm{em} 1, \mathrm{em} 2}, \mathrm{kOhm}$ & 1.79 & & 1.50 & \\
\hline
\end{tabular}

Table II. Geometrical parameters of pressure sensor chip PDA-NFL for 60, 5 and $1 \mathrm{kPa}$.

\begin{tabular}{|llll|}
\hline Geometrical Parameter (Fig. 3a) & Size, $\mu \mathrm{m}$ & & \\
\hline Pressure sensor chip PDA-NFL & $60 \mathrm{kPa}$ & $5 \mathrm{kPa}$ & $1 \mathrm{kPa}$ \\
\hline L & $4000 \pm 20$ & & \\
\hline H & $400 \pm 5$ & & \\
\hline A & $2260 \pm 20$ & & \\
W & $33 \pm 2$ & $9 \pm 2$ & \\
\hline D & $41 \pm 5$ & $23 \pm 5$ & $39 \pm 5$ \\
\hline Z & $490 \pm 50$ & $790 \pm 50$ & $270 \pm 50$ \\
\hline
\end{tabular}

NI Multisim software was used for evaluation of chip sensitivity and additional temperature error based on the design parameters. Some results are shown in Fig. 4. Comparison of pressure sensitivity of the circuits with BJT sensitive / not sensitive to pressure shows that stress-sensitive BJTs placed on the membrane can increase pressure sensitivity only by about 1-5\% [30-32].

Placing BJTs on the frame has some advantages: it allows for achieving more symmetrical layout of components and avoiding connections between active and passive components on the membrane. Pressure sensor chip PDA-NFL with BJTs located on the membrane (pressure-sensitive) was fabricated but did not function properly due to a mistake in layout. 
Theoretical model shows that electrical circuit PDA-NFL with V-NPN BJT is better than electrical circuit PDA-NFL with L-PNP BJT, for example for $60 \mathrm{kPa}$ range: sensitivity $\mathrm{S}_{\mathrm{V}-\mathrm{NPN}}=1.736 \mathrm{mV} / \mathrm{V} / \mathrm{kPa}$ and $\mathrm{S}_{\mathrm{L}-\mathrm{PNP}}$ $=1.402 \mathrm{mV} / \mathrm{V} / \mathrm{kPa}$, additional temperature error for zero signal $\mathrm{TCZ}_{\mathrm{V}-\mathrm{NPN}}=0.026 \% \mathrm{FS} /{ }^{\circ} \mathrm{C}$ and $\mathrm{TCZ} \mathrm{L}_{\mathrm{PNP}}=$ $0.584 \% \mathrm{FS} /{ }^{\circ} \mathrm{C}$. Parasitic current from emitter to substrate should be taken into account in the circuit utilizing L-PNP BJT (see Table II). This current exists even when p-n junction between epitaxial layer and substrate is closed. Analysis by TCAD shows that $67 \%$ of transistor current goes to the substrate. This fact has been confirmed experimentally. Therefore, section III contains only test data for pressure sensor chip PDA-NFL with V-NPN BJT located on the frame and not sensitive to pressure.

\section{lii. Experimental Data}

Pressure sensor chip with PDA-NFL was bonded to a silicon support and placed on Kovar case (Fig. 5) for testing of its characteristics. The silicon support consists of an intermediate element and a pedestal, which are connected by low-temperature glass. The sensor assembly allows for measuring differential pressure. All samples were exposed to temperature and pressure cycling to remove residual assembly stress before functional testing [33-37].

Pressure sensors with PDA-NFL chip were compared with similar products utilizing Wheatstone bridge circuit having the same or similar pressure range: 1) mass-fabricated $60 \mathrm{kPa}$ pressure sensor IPD60 (VNIIA), 2) high-sensitivity $5 \mathrm{kPa}$ CBMP sensor (in development) [38,39], 3) ultra-high sensitivity pressure sensor [22,23] mentioned in Introduction. This sensor was developed for $0.5 \mathrm{kPa}$ pressure range and its samples demonstrated sensitivity up to $66.0 \mathrm{mV} / \mathrm{V} / \mathrm{kPa}$. Data for 6 types of pressure sensors presented in Table III.

As it can be seen from Table III, sensors built with PDA-NFL chip have high sensitivity. In the $60 \mathrm{kPa}$ range, pressure sensor with PDA-NFL chip has 3.65 times higher sensitivity than IPD60 sensor although both sensors have the same membrane size. Pressure sensor with PDA-NFL chip for $5 \mathrm{kPa}$ has 2.2 times higher sensitivity, 7-8 times smaller hysteresis and improved repeatability compared to the CBMP pressure sensor even though CBMP sensor has $65 \%$ larger diaphragm area. Pressure sensor for $1 \mathrm{kPa}$ with PDANFL chip has lower sensitivity than the chip with peninsula-island [22,23]. Yet, if both chips would have the same diaphragm size, then sensitivity of PDA-NFL chip (proportional to squared membrane length) will be about $109.6 \mathrm{mV} / \mathrm{V} / \mathrm{kPa}$ or $66 \%$ higher. As PDA-NFL chip uses signal amplification, its mechanical structure is stronger and burst pressure is 2.5-5 times higher compared to the sensors with Wheatstone bridge [40].

Improvement of parameters of sensors with PDA-NFL chip is needed two areas. (1) The sensors have higher noise due to $1 / f$ noise of BJTs. The noise has been minimized by optimizing manufacturing process and reducing an active base thickness of BJT [41]. Output noise also can be reduced by averaging multiple measurements in sensors with ASIC. (2) PDA-NFL circuit contains eight PRs and high temperature sensitive BJTs resulting in higher zero output signal and 2-3 times higher temperature errors. 
These parameters can be improved through PR layout optimization and optimization of temperature characteristics of BJTs.

Table III. Output characteristics of pressure sensors chips: PDA-NFL, IPD60, CBMP and Peninsula-island. 


\begin{tabular}{|c|c|c|c|c|c|c|c|}
\hline \multicolumn{2}{|c|}{ Type of pressure sensor chip } & $\begin{array}{l}\text { PDA- } \\
\text { NFL }\end{array}$ & IPD60 & PDA-NFL & $\begin{array}{l}\text { CBMP } \\
{[38,39]}\end{array}$ & PDA-NFL & $\begin{array}{l}\text { Peninsula- } \\
\text { island [22, } \\
\text { 23] }\end{array}$ \\
\hline \multicolumn{2}{|c|}{ Pressure range } & \multicolumn{2}{|l|}{$60 \mathrm{kPa}$} & \multicolumn{2}{|l|}{$5 \mathrm{kPa}$} & \multicolumn{2}{|l|}{$1 \mathrm{kPa}$} \\
\hline \multicolumn{2}{|c|}{$\begin{array}{l}\text { Dimension of membrane } \\
\text { thin part, } \mathrm{mm}^{2}\end{array}$} & \multicolumn{2}{|c|}{$2.26 \times 2.26$} & $2.26 \times 2.26$ & $2.90 \times 2.90$ & $2.26 \times 2.26$ & $3.50 \times 3.50$ \\
\hline \multicolumn{2}{|c|}{$\begin{array}{l}\text { Number of samples in } \\
\text { statistics }\end{array}$} & 20 & 1200 & 22 & - & 14 & - \\
\hline \multicolumn{2}{|c|}{ Sensitivity $\mathrm{S}, \mathrm{mV} / \mathrm{V} / \mathrm{kPa}$} & 1.877 & 0.515 & 11.24 & 5.14 & 44.9 & 66.0 \\
\hline \multicolumn{2}{|c|}{$\begin{array}{l}\text { Zero pressure output signal } \\
\text { (Offset), mV/V }\end{array}$} & 6.8 & 3.0 & 8.0 & 1.3 & 14.0 & - \\
\hline \multicolumn{2}{|c|}{ Noise voltage, $\mu \mathrm{V} / \mathrm{V}$} & 3 & 0.8 & 3 & - & 12 & - \\
\hline \multicolumn{2}{|c|}{ Nonlinearity $2 \mathrm{~K}_{\mathrm{NL}}, \% \mathrm{FS}$} & 0.059 & 0.055 & 0.27 & 0.28 & $\begin{array}{l}0.26 \\
(\text { for } 0.5 \\
\mathrm{kPa})\end{array}$ & $\begin{array}{l}0.33 \\
(\text { for } 0.5 \\
\mathrm{kPa})\end{array}$ \\
\hline \multicolumn{2}{|c|}{ Hysteresis $\mathrm{H}, \% \mathrm{FS}$} & - & - & 0.03 & 0.26 & $\begin{array}{l}0.28 \\
(\text { for } 0.5 \\
\mathrm{kPa})\end{array}$ & $\begin{array}{l}0.36 \\
(\text { for } 0.5 \\
\mathrm{kPa})\end{array}$ \\
\hline \multicolumn{2}{|c|}{ Repeatability R, \%FS } & - & - & 0.08 & 0.53 & $\begin{array}{l}0.42 \\
\text { (for } 0.5 \\
\mathrm{kPa})\end{array}$ & $\begin{array}{l}0.67 \\
(\text { for } 0.5 \\
\mathrm{kPa})\end{array}$ \\
\hline \multicolumn{2}{|c|}{$\begin{array}{l}\text { Zero change after flipping } \\
\text { sensor in gravity field, } \\
\mu \mathrm{V} / \mathrm{V} / \mathrm{g}\end{array}$} & - & - & 11 & - & 13 & 28 \\
\hline \multicolumn{2}{|c|}{ Burst pressure $\mathrm{P}_{\text {burst }}, \mathrm{kPa}$} & 1600 & & 600 & - & 500 & 105 \\
\hline \multirow{2}{*}{$\begin{array}{l}\text { Output } \\
\text { changing } \\
\text { after } \\
\text { pressure } \\
\text { overload }\end{array}$} & of offset, \%FS & 0.006 & 0.004 & 0.023 & - & 0.083 & - \\
\hline & $\begin{array}{l}\text { of pressure } \\
\text { sensitivity, \%FS }\end{array}$ & 0.069 & 0.072 & 0.081 & - & 0.061 & - \\
\hline \multirow{2}{*}{$\begin{array}{l}\text { Long-term } \\
\text { stability }\end{array}$} & of offset, \%FS & 0.007 & 0.002 & 0.032 & - & 0.122 & 0.138 \\
\hline & $\begin{array}{l}\text { of pressure } \\
\text { sensitivity, \%FS }\end{array}$ & 0.006 & 0.003 & 0.023 & - & 0.166 & - \\
\hline \multirow{2}{*}{$\begin{array}{l}\text { Thermal } \\
\text { hysteresis } \\
\text { of zero, } \\
\% F S\end{array}$} & $\left(-30 \ldots+20^{\circ} \mathrm{C}\right)$ & 0.065 & 0.033 & 0.042 & - & 0.341 & - \\
\hline & $\left(+20 \ldots+60^{\circ} \mathrm{C}\right)$ & 0.045 & 0.025 & 0.050 & - & 0.262 & - \\
\hline \multirow{2}{*}{$\begin{array}{l}\text { Thermal } \\
\text { hysteresis } \\
\text { of span, } \\
\% F S\end{array}$} & $\left(-30 \ldots+20^{\circ} \mathrm{C}\right)$ & 0.042 & 0.018 & 0.189 & - & 0.611 & - \\
\hline & $\left(+20 \ldots+60^{\circ} \mathrm{C}\right)$ & 0.017 & 0.012 & 0.061 & - & 0.343 & - \\
\hline
\end{tabular}




\begin{tabular}{|llllllll|}
\begin{tabular}{|l} 
Thermal \\
coefficient
\end{tabular} & $\left(-30 \ldots+20^{\circ} \mathrm{C}\right)$ & 0.007 & 0.003 & 0.014 & - & 0.092 & 0.165 \\
$\begin{array}{l}\text { of zero, } \\
\left(\% /{ }^{\circ} \mathrm{C}\right) \mathrm{FS}\end{array}$ & $\left(+20 \ldots+60^{\circ} \mathrm{C}\right)$ & 0.010 & 0.002 & 0.012 & 0.013 & 0.096 & \\
\hline $\begin{array}{l}\text { Thermal } \\
\text { coefficient }\end{array}$ & $\left(-30 \ldots+20^{\circ} \mathrm{C}\right)$ & 0.020 & 0.043 & 0.222 & - & 0.633 & - \\
$\begin{array}{l}\text { of span, } \\
\left(\% /{ }^{\circ} \mathrm{C}\right) \mathrm{FS}\end{array}$ & $\left(+20 \ldots+60^{\circ} \mathrm{C}\right)$ & 0.045 & 0.034 & 0.204 & 0.116 & 0.634 & - \\
\hline
\end{tabular}

\section{Iv. Conclusion}

The presented project demonstrates the opportunity for improvement of piezoresistive pressure sensors by on-chip integration of piezosensitive differential amplifier on BJTs. Theoretical model for pressure sensor PDA-NFL was created using both analytical calculations and software modeling. High-sensitivity sensing elements for pressure ranges $(60 \mathrm{kPa}, 5 \mathrm{kPa}$ and $1 \mathrm{kPa})$ have been fabricated and tested. Pressure sensor with PDA-NFL showed significant advantages compared to piezoresistive pressure sensors for similar pressure ranges with Wheatstone bridge circuit. Directions for further improvement of pressure sensors with PDA-NFL electrical circuit on the chip are discussed.

\section{Declarations}

Competing interests: The authors declare no competing interests.

\section{References}

1. C. Li, J. Xie, F. Cordovilla, J. Zhou, R. Jagdheesh, J. L. Ocaña, “Design, fabrication and characterization of an annularly grooved membrane combined with rood beam piezoresistive pressure sensor for low pressure measurements", Sensors and Actuators A: Physical, vol. 279, pp. 525- 536, 2018.

2. B. Zhu, X. Zhang, Y. Zhang, S. Fatikow, "Design of diaphragm structure for piezoresistive pressure sensor using topology optimization," Struct Multidisc Optim, vol. 55, pp. 317-329, 2017.

3. X. Meng, Y. Zhao, "The Design and Optimization of a Highly Sensitive and Overload-Resistant Piezoresistive Pressure Sensor," Sensors, vol. 16, no. 3, 348, 2016.

4. M. Basov, D. Prigodskiy, "Investigation of High Sensitivity Piezoresistive Pressure Sensors at UltraLow Differential Pressures," IEEE Sensors Journal, vol. 20, no. 14, pp. 7646-7652, 2020.

5. M. Basov, D. Prigodskiy, “Development of High-Sensitivity Piezoresistive Pressure Sensors for -0.5... kPa," Journal of Micromechanics and Microengineering, vol. 30, no. 10, 105006, 2020.

6. Z. Yu, Y. Zhao, L. Sun, B. Tian, Z. Jiang, "Incorporation of Beams into Bossed Diaphragm for a High Sensitivity and Overload Micro Pressure Sensor," Review Scientific Instruments, vol. 84, 015004, 2013.

7. Z. Yu, Y. Zhao, L. Li, C. Li, Y. Liu, B. Tian, "Realization of a Micro Pressure Sensor with High Sensitivity and Overload by Introducing Beams and Islands," Microsyst. Technol., vol. 21, pp.739-747, 2015. 
8. A.V. Tran, X. Zhang, B. Zhu, "Mechanical Structural Design of a Piezoresistive Pressure Sensor for Low-Pressure Measurement: A Computational Analysis by Increases in the Sensor Sensitivity," Sensors, vol. 18, 2023, 2018.

9. T. Guan, F. Yang, W. Wang, X. Huang, B. Jiang, D. Zhang, "The Design and Analysis of Piezoresistive Shuriken-Structured Diaphragm Micro-Pressure Sensors," Journal of Microelectromechanical Systems, vol. PP(99), pp. 1-9, 2016.

10. S. Marco, J. Samitier, O. Ruiz, J.R. Morante, J. Esteved, “High-Performance Piezoresistive Pressure Sensors for Biomedical Applications Using Very Thin Structured Membranes," IOP Measurement Science and Technology, vol. 7, pp. 1195-1203, 1996.

11. J. Wang, X. Xia, X. Li, "Monolithic integration of pressure plus acceleration composite TPMS sensors with a single-sided micromachining technology," Journal of Microelectromechanical Systems, vol. 21, pp. 284-293, 2012.

12. C.T. Seo, Y.M. Kim, J.K. Shin, J.H. Lee, "A Novel Comb-Type Differential Pressure Sensor with Silicon Beams Embedded in a Silicone Rubber Membrane," Jpn. J. Appl. Phys., vol. 43, pp. 2046-2049, 2004.

13. X. Huang, D. Zhang, "A High Sensitivity and High Linearity Pressure Sensor Based on a Peninsulastructured Diaphragm for Low-Pressure Ranges," Sensors and Actuators A: Physical, vol. 216, pp. 176-189, 2014.

14. H.-P. Phan, K.M. Dowling, T.K. Nguyen, T. Dinh, D.G. Senesky, T. Namazu, D.V. Dao, N.-T. Nguyen, "Highly sensitive pressure sensors employing $3 \mathrm{C}$-SiC nanowires fabricated on a free standing structure," Materials \& Design, vol. 156, pp.16-21, 2018.

15. X. Huang, D. Zhang, "A High Sensitivity and High Linearity Pressure Sensor Based on a Peninsulastructured Diaphragm for Low-Pressure Ranges," Sensors and Actuators A: Physical, vol. 216, pp. 176-189, 2014.

16. J.R. Mallon, F. Pourahmadi, K. Petersen, P. Barth, T. Vermeulen, J. Bryzek, “Low-Pressure Sensors Employing Bossed Diaphragms and Precision Etch-Stopping," Sensors and Actuators A: Physical, vol. 21, pp. 89-95, 1990.

17. H. Sandmaier, K. Kuhl, "A square-diaphragm piezoresistive pressure sensor with a rectangular central boss for low-pressure ranges," IEEE Transactions on Electron Devices, vol. 40, pp. 1754-1759, 1993.

18. A. Berns, U. Buder, E. Obermeier, A. Wolter, A. Leder, "AeroMEMS sensor array for high-resolution wall pressure measurements, Sensors and Actuators A: Physical," vol. 132, pp. 104-111, 2006.

19. C.H. Je, S.Q. Lee, W.S. Yang, "High Sensitivity Surface Micromachined Absolute Pressure Sensor," Procedia Engineering, vol. 168, pp.725-728, 2016.

20. L. Li, N. Belov, M. Klitzke, J-S. Park, "High Performance Piezoresistive Low Pressure Sensors," IEEE Sensors Conference, pp. 1406-1408, November 2016.

21. P.W. Barth, "Silicon fusion bonding for fabrication of sensors, actuators and microstructures," Sensors and Actuators A: Physical, vol. 23, pp. 919-926, 1990.

22. Zhao, L., Xu, T., Hebibul, R., Jiang, Z., Ding, J., Peng, N., Guo, X., Xu, Y., Wang, H., Zhao, Y., "A Bossed Diaphragm Piezoresistive Pressure Sensor with a Peninsula-Island Structure for the Ultra-Low- 
Pressure Range with High Sensitivity," IOP Measurement Science and Technology, vol. 27, 124012, August 2017.

23. T. Xu, H. Wang, Y. Xia, Z. Zhao, M. Huang, J. Wang, L. Zhao, Y. Zhao, Z. Jiang, “Piezoresistive pressure sensor with high sensitivity for medical application using peninsula-island structure," Front. Mech. Eng., vol. 12, pp. 546-553, 2017.

24. M. Basov, "Development of High-Sensitivity Pressure Sensor with On-chip Differential Transistor Amplifier," J. Micromech. Microeng., vol. 30, no. 6, 065001, 2020.

25. M. Basov, "High-sensitivity MEMS pressure sensor utilizing bipolar junction transistor with temperature compensation," Sensors and Actuators A: Physical, vol. 303, 111705, 2020.

26. M. Basov, "Ultra-High Sensitivity MEMS Pressure Sensor Utilizing Bipolar Junction Transistor for Pressures Ranging from -1 to 1 kPa," IEEE Sensors Journal, vol. 21, no. 4, pp. 4357-4364, 2021.

27. M. Basov, "High sensitive, linear and thermostable pressure sensor utilizing bipolar junction transistor for $5 \mathrm{kPa}$," Physica scipta, vol. 96, no. 6, 065705, 2021.

28. M.V. Basov, D.M. Prigodskiy, D.A. Holodkov, "Modeling of Sensitive Element for Pressure Sensor Based on Bipolar Piezotransistor," Sensors and Systems, vol. 6, pp. 17-24, 2017.

29. M.V. Basov, D.M. Prigodskiy, "Investigation of a Sensitive Element for the Pressure Sensor Based on a Bipolar Piezotransistor," Nano- and Microsystem Technology, vol. 19, no. 11, pp. 685-693, 2017.

30. F. Fruett, G.C.M. Meijer, "A New Sensor Structure Using the Piezojunction Effect in PNP Lateral Transistor," Sensors and Actuators: A: Physical, vol. 92, no. 1-3, pp. 197-202, 2001.

31. J. Creemer, F. Fruett, G.C.M. Meijer, P.J. French, "The Piezojunction Effect in Silicon Sensors and Circuits and Its Relation to Piezoresistance," IEEE Sens. J., vol. 1, pp. 98-108, 2001.

32. B.M. Wilamowski, J.D. Irwin, The industrial Electronics Handbook. Fundamentals of industrial electronics, Taylor and Francis Group, Boca Raton, 2011, pp. 11.1-11.11.

33. Å. Sandvand, E. Halvorsen, K. E. Aasmundtveit, H. Jakobsen, "Identification and Elimination of HygroThermo- Mechanical Stress-Effects in a High-Precision MEMS Pressure Sensor", Journal of Microelectromechanical Systems, vol. 26, pp. 415-423, 2017.

34. K. Birkelund, P. Gravesen, S. Shiryaev, P. B. Rasmussen, M. D. Rasmussen, "High-pressure silicon sensor with low-cost packaging," Sensors and Actuators A: Physical, vol. 92, pp. 16-22, 2001.

35. S. Guo, H. Eriksen, K. Childress, A. Fink, M. Hoffman, "High temperature smart-cut SOI pressure sensor," Sensors and Actuators A: Physical, vol. 154, pp. 255-260, 2009.

36. Y. Hamid, D.A. Hutt, D.C. Whalley, R. Craddock, "Relative contributions of packaging elements to the thermal hysteresis of a MEMS pressure sensor," Sensors, vol. 20, 1727, 2020.

37. M. Basov, "Schottky diode temperature sensor for pressure sensor," Sensors and Actuators A: Physical, vol. 331, 112930, 2021.

38. A. V. Tran, X. Zhang, B. Zhu, "The Development of a New Piezoresistive Pressure Sensor for Low Pressures," IEEE Transactions on Industrial Electronics, vol. 65, no. 8, pp. 6487-6496, 2018. 
39. A.V. Tran, X. Zhang, B. Zhu, "Effects of temperature and residual stresses on the output characteristics of a piezoresistive pressure sensor," IEEE Access, vol. 7, pp. 27668-27676, 2019.

40. T. Kober, R. Werthschützky, "Wafer Level Processing of Overload-Resistant Pressure Sensors," Procedia Engineering, vol. 47, pp. 615-618, 2012.

41. K.C. Katuri, S. Asrani, M.K. Ramasubramanian, "Intraocular Pressure Monitoring Sensors," IEEE Sensors Journal, vol. 8, pp. 12-19, 2008.

\section{Figures}

\section{Figure 1}

Pressure sensor chip PDA-NFL: a) electrical circuit, b) top view.

\section{Figure 2}

Dependence of gain $\beta$ on collector current (by TCAD software) for: a) V-NPN BJT, b) L-PNP BJT.

\section{Figure 3}

Membrane of pressure sensor chip PDA-NFL: a) structure overview, b) stress distribution (von Mises) between RI by ANSYS in $1 \mathrm{kPa}$ chip.

\section{Figure 4}

Parameters of PDA-NFL circuits with non-deformable BJT V-NPN and for $60 \mathrm{kPa}$ range calculated by NI Multisim on a) pressure $\triangle \mathrm{P}=100 \mathrm{kPa}, \mathrm{b}$ ) temperature (parameters of left circuit branch has $\mathrm{T}=37^{\circ} \mathrm{C}$, parameters of right circuit branch $-\mathrm{T}=27^{\circ} \mathrm{C}$ ). 


\section{Figure 5}

(a) Pressure sensor PDA-NFL without cap, (b) assembly drawing. 